\title{
FORMULASI MINYAK-MINYAK MENGUAP MENJADI SEDIAAN BALSEM COUNTERIRRITANT
}

\author{
Iskandar zulkarnain *), Aminullah **) \\ ${ }^{*}$ Fakultas Farmasi Universitas Muslim Indonesia \\ ${ }^{* *}$ Fakultas Farmasi Universitas Hasanuddin \\ Email : izukaahmad@yahoo.com
}

\begin{abstract}
Volatile oils have efficacy as a counterirritant. Formulation of valitel oils into counterirritant ointment preparations. The research objective of volatile oils formulations into stable dosage balm. The study conducted with qualitative examination of all the materials used. Test parameters measured are fatty oils, solubility in alcohol, the determination of optical rotation, refractive index and specific gravity. Formulation and manufacture of balm performed using the hydrocarbon base cera alba and Vaseline alba. Balm that has to be evaluated by storing at extreme temperature cycles. Parameters measured werw organoleptis examination, measurementof viscosity and yieldvalue determination, as well as examinationof heavy metal and microbial contamination. The result obtained throughout the testing on a qualitative examination of the raw material requirement. The test result organoleptic is white, odoless typical, with a appropriate consistency. Viscosity of preparation did notchange significantly. Preparation do not contain heavy metal and harmful microbes.
\end{abstract}

Key Word : volatile oils, balm, stability

\section{PENDAHULUAN}

Obat merupakan salah satu penunjang terwujudnya derajat kesehatan yang optimal. Untuk itu berbagai upaya dilakukan untuk tersedianya obat dalam jenis dan jumlahnya yang cukup, khasiat dan mutunya terjamin serta harganya yang terjangkau [1].

Dalam rangka upaya meningkatkan pelayanan kesehatan masyarakat di Indonesia, obat tradisional memiliki peluang sebagai salah satu alternatif pengobatan yang cukup potensial. Dengan keaneka ragaman jenis tanaman yang ada, membuka peluang yang luas untuk memperoleh obat baru. Untuk itu, tanaman obat sebagai salah satu sumber obat tradisional yang secara empiris telah terbukti berkhasiat, harus dapat dikembangkan dan selanjutnya 
dapat dimanfaatkan dengan sebaikbaiknya [2].

Masyarakat menggunakan obat tradisional dalam bentuk jamu godokan, rebusan, perasan atau dengan cara menggosokkan langsung pada bagian yang sakit. Bentuk sediaan yang masih tradisional menjadikan penggunaan yang kurang efektif dan efisien. Perkembangan ilmu farmasi memungkinkan obat tradisional diusahakan untuk ditingkatkan mutu, keamanan dan efesiensinya serta bentuk dan kemasan untuk bersaing dengan obat modern [2].

Kebanyakan masyarakat, terutama orang-orang lanjut usia kerapkali dihinggapi nyeri otot. Jenis ini ada hubungannya dengan proses menua dari semua organ, termasuk otot. Semua jaringan menjadi lebih mudah dirusak, sedangkan aliran masuk dari bahan bakar (makanan) dan pembuangan zat-zat hasil penguraian tidak berlangsung optimal lagi. Umumnya sejenis kejang dan nyeri, yang kerapkali menghinggapi betis orang-orang tua, pada waktu sebelum tidur atau ditengah malam. Kaki-kakinya melakukan gerakan yang tak sengaja yang tidak dapat dikendalikan, sehingga tidurnya sangat bias terganggu [4].
Mahalnya obat-obat sintetik modern, memberikan alternative tersendiri bagi masyarakat untuk menggunakan dan mengembangkan tanaman yang sesuai pengalaman dapat digunakan untuk meringankan nyeri pada otot maupun persendian. Tanaman yang acapkali digunakan dan umumnya tersedia dalam bentuk minyak gosok seperti tanaman yang mengandung suatu zat antinyeri seperti gandapura dan tanaman yang mengandung minyak terbang yang memiliki khasiat mematikan rasa (dan nyeri), mengendurkan kejang, melebarkan pembuluh dan bersifat antiseptic seperti minyak kayu putih, minyak permen, minyak cengkeh, minyak sereh yang bila digosokkan pada kulit, akan memberikan rasa dingin, yang disusul dengan perasaan hangat dan nikmat [4].

Berdasarkan hal tersebut, maka penulis tertarik untuk membuat formula dalam bentuk sediaan berupa balsem yang menggunakan bahan alam dari tumbuhan berupa minyak kayu putih, minyak cengkeh, minyak sereh, minyak permen, minyak gandapura dan minyak terpentin yang diindikasikan untuk meringankan nyeri otot (counterirritant) dan menghangatkan badan. Penyusunan formula ini bertujuan untuk membuat 
As-Syifaa Vol 04 (01) : Hal. 42-57, Juli 2012 ISSN : 2085-4714

sediaan balsem agar penggunaan

Pemeriksaan kualitatif

obat tradisional dapat lebih efisien dan bermutu serta memenuhi syarat baik khasiat maupun keamanan penggunaannya.

Balsem adalah obat gosok dengan kepekatan seperti salep, sedangkan salep adalah sediaan setengah padat yang diperuntukkan untuk pemakaian topikal pada kulit atau selaput lendir. Salep dapat bervariasi berdasarkan komposisi, konsistensi dan tujuan penggunaannya. Banyak faktor yang mempengaruhi dalam pemilihan dasar/basis salep. Sifat bahan obat, kestabilan dan aksi teraupetik yang diinginkan adalah penting untuk diperhatikan. Basis salep teraupetik bertindak sebagai pembawa komponen obat yang ditujukan untuk mengalami absorbsi perkutan yaitu absorbsi melalui kulit ke dalam jaringan dalam dan pembuluh darah.

\section{METODE PENELITIAN}

\section{A. Alat dan bahan yang digunakan}

Bahan yang digunakan adalah minyak kayu putih, miyak cengkeh, minyak sereh, minyak terpentin, minyak gandapura, mentol, kamfer, cera alaba dan vaselin putih.

\section{B. Pemeriksaan kualitatif Bahan} Baku

dilakukan terhadap minyak kayu putih, minyak cengkeh, minyak sereh, minyak terpentin, minyak gandapura. Parameter yang diukur berupa uji minyak lemak, kelarutan dalam alkohol, pengukuran rotasi optik, indeks bias dan penentuan bobot jenis.

\section{Rancangan formulasi}

Formula balsam dirancang dengan menggunakan basis absorpsi dengan menggunakan basis cera alba dan vaselin putih, sedang minyak-minyak menguap menjadi bahan aktif.

\section{Evaluasi kestabilan sediaan}

Evaluasi kestabilan balsem minyak menguap pada pengujian sebelumnya menggunakan variasi konsentrasi basis, dilakukan sebelum dan setelah penyimpanan dipercepat. Penyimpanan dipercepat dilakukan pada suhu antara $5{ }^{\circ} \mathrm{C}$ dan $35^{\circ} \mathrm{C}$, masing-masing 12 jam selama 10 siklus. Parameter yang diuji adalah pemeriksaan organoleptik, pengukuran viskositas, penentuan nilai yield, pemeriksaan cemaran logam, pemeriksaan Tembaga dan Timbal, pemeriksaan cemaran mikroba 


\section{HASIL PENELITIAN}

\section{A. Pemeriksaan kualitatif Bahan Baku}

Tabel 1. Hasil Pengukuran indeks bias dan rotasi optik bahan baku

\begin{tabular}{cccccc}
\hline \multirow{2}{*}{ No } & \multirow{2}{*}{ Bahan Baku } & \multicolumn{2}{c}{ Rotasi Optik } & \multicolumn{2}{c}{ Indeks Bias } \\
\cline { 2 - 6 } & Hasil & Pustaka & Hasil & Pustaka \\
\hline 1 & Minyak Kayu Putih & $+1,95$ & -4 sampai +1 & 1,4545 & $1,464-1,472$ \\
2 & Minyak Cengkeh & $-1,2$ & 0 sampai $-1,5$ & 1,5362 & $1,528-1,537$ \\
3 & Minyak Sereh & $+2,56$ & -5 sampai +2 & 1,4611 & $1,468-1,473$ \\
4 & Minyak Gandapura & $+0,56$ & - & 1,5312 & $1,535-1,538$ \\
5 & Minyak Terpentin & $+29,05$ & +32 & 1,4620 & $1,464-1,478$ \\
6 & Minyak Permen & $-22,95$ & -30 sampai -16 & 1,4550 & $1,460-1,470$ \\
\hline
\end{tabular}

Tabel 2. Hasil Pengukuran Berat Jenis Bahan Baku

\begin{tabular}{cccccc}
\hline No & Bahan Baku & $\begin{array}{c}\text { Berat Pikno } \\
\text { kosong } \\
\text { [gram] }\end{array}$ & $\begin{array}{c}\text { Berat Pikno + } \\
\text { sampel } \\
\text { [gram] }\end{array}$ & $\begin{array}{c}\text { BJ } \\
\text { sampel }\end{array}$ & Pustaka \\
\hline 1 & Minyak Kayu Putih & 23,797 & 45,989 & 0,9325 & $0,910-0,923$ \\
2 & Minyak Cengkeh & 23,798 & 49,081 & 1,0624 & $1,041-1,054$ \\
3 & Minyak Sereh & 23,799 & 45,180 & 0,8983 & $0,880-0,895$ \\
4 & Minyak Gandapura & 23,797 & 52,170 & 1,1922 & $1,176-1,182$ \\
5 & Minyak Terpentin & 23,798 & 44,506 & 0,8701 & $0,848-0,865$ \\
6 & Minyak Permen & 23,797 & 45,717 & 0,9001 & $0,897-0,921$ \\
\hline
\end{tabular}

Tabel 3. Hasil Pemeriksaan Bahan Baku Secara Kualitatif

\begin{tabular}{|c|c|c|c|c|c|}
\hline No & Nama bahan & Perlakuan & Hasil Pustaka & Hasil Pengamatan & Ket \\
\hline \multirow{3}{*}{1} & \multirow{3}{*}{ Mentol } & $\begin{array}{l}\text { Digerus bersama } \\
\text { Kamfer sama berat }\end{array}$ & Mencair & Mencair & + \\
\hline & & $\begin{array}{l}\text { Digerus bersama } \\
\text { kloralhidrat sama } \\
\text { berat }\end{array}$ & Mencair & Mencair & + \\
\hline & & $\begin{array}{l}\text { Digojog dengan } \\
\mathrm{H}_{2} \mathrm{SO}_{4} \mathrm{P} \text { lalu } \\
\text { dipanaskan }\end{array}$ & $\begin{array}{l}\text { Merah muda } \\
\text { kecoklatan dan } \\
\text { bau mentol } \\
\text { hilang }\end{array}$ & $\begin{array}{l}\text { Merah muda } \\
\text { kecoklatan serta bau } \\
\text { mentol hilang }\end{array}$ & + \\
\hline \multirow{5}{*}{2} & \multirow{5}{*}{ Kamfer } & $\begin{array}{l}\text { Digerus dengan } \\
\text { kloralhidrat }\end{array}$ & Mencair & Mencair & + \\
\hline & & $\begin{array}{l}\text { Digerus dengan } \\
\text { mentol }\end{array}$ & Mencair & Mencair & + \\
\hline & & $\begin{array}{l}\text { Digerus dengan } \\
\text { resorsinol }\end{array}$ & Mencair & Mencair & + \\
\hline & & $\begin{array}{l}\text { Digerus dengan } \beta \text { - } \\
\text { nafthol }\end{array}$ & Mencair & Mencair & + \\
\hline & & $\begin{array}{l}\text { Digerus dengan } \\
\text { timol }\end{array}$ & Mencair & Mencair & + \\
\hline 3 & Vaselin Putih & $\begin{array}{l}3 \mathrm{~g} \text { Vaselin [+] } 6 \mathrm{ml} \\
\mathrm{H}_{2} \mathrm{SO}_{4} \mathrm{P}\end{array}$ & $\begin{array}{l}\text { Coklat dalam } \\
\text { waktu } 30 \text { menit }\end{array}$ & $\begin{array}{l}\text { Coklat dalam waktu } \\
40 \text { menit }\end{array}$ & + \\
\hline \multirow[t]{2}{*}{4} & \multirow[t]{2}{*}{$\begin{array}{l}\text { Minyak Kayu } \\
\text { Putih }\end{array}$} & $\begin{array}{l}\text { Campuran } 5 \text { g } \\
\text { dengan } 1 \text { g serbuk } \\
\text { iodium } P \text {, hangatkan } \\
\text { pada suhu } 50^{\circ}, \\
\text { dinginkan }\end{array}$ & $\begin{array}{l}\text { Membeku, } \\
\text { bentuk hablur }\end{array}$ & $\begin{array}{l}\text { Membeku, bentuk } \\
\text { hablur }\end{array}$ & + \\
\hline & & + lodium & Larut & Larut & + \\
\hline
\end{tabular}




\begin{tabular}{|c|c|c|c|c|c|}
\hline & & Uji minyak lemak & $\begin{array}{l}\text { Tidak ada } \\
\text { endapan }\end{array}$ & Tidak ada endapan & - \\
\hline & & + Alkohol & Larut & Larut & + \\
\hline \multirow[t]{3}{*}{5} & \multirow[t]{3}{*}{$\begin{array}{l}\text { Minyak } \\
\text { cengkeh }\end{array}$} & $\begin{array}{l}\text { Dilarutkan } 2 \text { tetes } \\
\text { minyak cengkeh } \\
\text { dalam } 4 \mathrm{ml} \text { etanol } \\
\text { dan ditambahkan } 2 \\
\text { tetes } \mathrm{FeCl}_{3}\end{array}$ & Warna hijau & Warna hijau & + \\
\hline & & Uji minyak lemak & $\begin{array}{l}\text { Tidak ada } \\
\text { endapan }\end{array}$ & Tidak ada endapan & + \\
\hline & & + Alkohol & Larut & Larut & + \\
\hline \multirow{4}{*}{6} & \multirow{4}{*}{ Minyak sereh } & $\begin{array}{l}+5 \text { tetes larutan } \\
\text { besi [III] klorida } P \\
5 \% \mathrm{~b} / \mathrm{v},\end{array}$ & $\begin{array}{l}\text { terjadi warna } \\
\text { biru. }\end{array}$ & $\begin{array}{l}\text { terjadi warna violet } \\
\text { tua }\end{array}$ & + \\
\hline & & $\begin{array}{l}+5 \text { tetes larutan } \\
\text { kalium hidroksida }\end{array}$ & Kuning & Kuning & + \\
\hline & & Uji minyak lemak & $\begin{array}{l}\text { Tidak ada } \\
\text { endapan }\end{array}$ & Tidak ada endapan & + \\
\hline & & + Alkohol & Larut & Larut & + \\
\hline \multirow[t]{2}{*}{7} & \multirow{2}{*}{$\begin{array}{l}\text { Minyak } \\
\text { terpentin }\end{array}$} & Uji minyak lemak & $\begin{array}{l}\text { Tidak ada } \\
\text { endapan }\end{array}$ & Tidak ada endapan & + \\
\hline & & + Alkohol & Larut & Larut & + \\
\hline \multirow[t]{3}{*}{8} & \multirow[t]{3}{*}{$\begin{array}{l}\text { Minyak } \\
\text { gandapura }\end{array}$} & $\begin{array}{l}\text { Kocok } 1 \text { tetes } \\
\text { dengan } \\
\text { kurang } 5 \mathrm{ml} \text { lebih } \\
\text { tambahkan } 1 \text { tetes } \\
\text { larutan besi } \\
\text { klorida } \mathrm{P},\end{array}$ & $\begin{array}{l}\text { terjadi warna } \\
\text { violet tua }\end{array}$ & $\begin{array}{l}\text { terjadi warna violet } \\
\text { tua }\end{array}$ & + \\
\hline & & Uji minyak lemak & $\begin{array}{l}\text { Tidak ada } \\
\text { endapan }\end{array}$ & Tidak ada endapan & + \\
\hline & & + Alkohol & Larut & Larut & + \\
\hline \multirow[t]{2}{*}{9} & \multirow{2}{*}{$\begin{array}{l}\text { Minyak } \\
\text { permen }\end{array}$} & Uji minyak lemak & $\begin{array}{l}\text { Tidak ada } \\
\text { endapan }\end{array}$ & Tidak ada endapan & + \\
\hline & & + Alkohol & Larut & Larut & + \\
\hline
\end{tabular}

Keterangan,

+ : Hasil Sesuai dengan Pustaka

\section{B. Evaluasi kestabilan sediaan}

\section{Pemeriksaan organoleptik}

Formula yang dihasilkan berwarna putih, berbau khas, dengan konsistensi yang sesuai. Setelah penyimpanan dipercepat, formula tidak mengalami perubahan warna, bau dan konsistensinya 
Tabel 4, Hasil pengukuran viskositas balsam minyak menguap pada $50 \mathrm{rpm}$ dengan viskometer Brookfield.

\begin{tabular}{rcc}
\hline Kondisi & Replikasi & Formula \\
\hline \multirow{3}{*}{ Sebelum penyimpanan } & 1 & 10780 \\
\cline { 2 - 3 } & 2 & 10710 \\
\cline { 2 - 3 } & 3 & 10680 \\
\hline Rata-rata & & $\mathbf{1 0 7 2 3 , 3 3}$ \\
\cline { 2 - 3 } Setelah penyimpanan & 1 & 10190 \\
\cline { 2 - 3 } & 2 & 10760 \\
\hline Rata-rata & 3 & 9640 \\
\hline
\end{tabular}

Tabel 5. Hasil pengukuran viskositas balsam minyak menguap pada $50 \mathrm{rpm}$ dengan viskometer Brookfield.

\begin{tabular}{cccc}
\hline Kondisi & rpm & \multicolumn{2}{c}{ Formula } \\
\hline & 5 & 48200 & 47900 \\
Sebelum penyimpanan & 10 & 32400 & 31620 \\
& 20 & 21100 & 20460 \\
& 30 & 15810 & 15120 \\
& 50 & 11220 & 11220 \\
\hline \multirow{3}{*}{ Setelah penyimpanan } & 5 & 86400 & 84000 \\
& 10 & 46200 & 46020 \\
& 20 & 26240 & 25620 \\
& 30 & 18620 & 18060 \\
& 50 & 12640 & 12640 \\
\hline
\end{tabular}

Tabel 6. Pemeriksaan cemaran logam

\begin{tabular}{|c|c|c|c|c|c|}
\hline No & Logam & Perlakuan & Hasil Pustaka & Hasil Pengamatan & ket \\
\hline 1 & $\begin{array}{l}\text { Tembaga } \\
{\left[\mathrm{Cu}^{2+}\right]}\end{array}$ & $\begin{array}{l}10 \mathrm{~g} \rightarrow \begin{array}{l}\text { cawan kurs, } \\
\text { dipanaskan }\end{array} \\
\text { sampai mengarang lalu } \\
\text { diabukan, dinginkan }\end{array}$ & & Tidak ada sisa abu & - \\
\hline 2 & Timbal $\left[\mathrm{Pb}^{2+}\right]$ & $\begin{array}{l}10 \mathrm{~g} \rightarrow \begin{array}{l}\text { cawan kurs, } \\
\text { dipanaskan }\end{array} \\
\text { sampai mengarang lalu } \\
\text { diabukan, dinginkan }\end{array}$ & & Tidak ada sisa abu & - \\
\hline \multirow{2}{*}{3} & \multirow{2}{*}{ Raksa $\left[\mathrm{Hg}^{2+}\right]$} & Filtrat [+] $\mathrm{NaOH} 2 \mathrm{M}$ & Endapan hitam & Larutan kuning & - \\
\hline & & Filtrat $[+] \mathrm{HCl} 0,5 \mathrm{M}$ & Endapan putih & Larutan kuning & - \\
\hline \multirow[b]{2}{*}{4} & \multirow[b]{2}{*}{ Arsen $\left[\mathrm{As}^{2+}\right]$} & Filtrat $[+] \mathrm{AgNO}_{3} 0,1 \mathrm{M}$ & Endapan kuning & Tidak terbentuk endapan & - \\
\hline & & $\begin{array}{l}\text { Filtrat [+] serbuk seng [+] } \\
\mathrm{H}_{2} \mathrm{SO}_{4} \text {, sumbat dengan } \\
\text { kapas yang dibasahi } \\
\text { timbal asetat. Taruh } \\
\text { kertas sarinng yang telah } \\
\text { ditetesi } \mathrm{AgNO}_{3} \text { di puncak } \\
\text { tabung }\end{array}$ & $\begin{array}{l}\text { Noda coklat } \\
\text { kuning hingga } \\
\text { hitam pada kertas } \\
\text { saring }\end{array}$ & $\begin{array}{l}\text { Tidak terdapat noda pada } \\
\text { kertas saring }\end{array}$ & - \\
\hline
\end{tabular}

Keterangan,

- : Tidak Mengandung logam berbahaya 
As-Syifaa Vol 04 (01) : Hal. 42-57, Juli 2012

ISSN : 2085-4714

Tabel 7. Pemeriksaan cemaran mikroba

\begin{tabular}{clcccc}
\hline No & Pemeriksaan & Medium & $\begin{array}{c}\text { Hasil positif } \\
\text { sesuai pustaka }\end{array}$ & $\begin{array}{c}\text { Hasil } \\
\text { pengamatan }\end{array}$ & Keterangan \\
\hline 1 & $\begin{array}{l}\text { Angka Lempeng } \\
\text { Total Bakteri }\end{array}$ & NA & $\leq 3 \times 10^{3} \mathrm{kol} / \mathrm{g}$ & $2,0 \times 10^{2} \mathrm{kol} / \mathrm{g}$ & $\begin{array}{c}\text { Memenuhi } \\
\text { syarat }\end{array}$ \\
\hline 2 & $\begin{array}{l}\text { Staphylococcus } \\
\text { aureus }\end{array}$ & $\begin{array}{c}\text { PW } \\
\text { VJA }\end{array}$ & $\begin{array}{c}\text { Koloni hitam zona } \\
\text { kuning }\end{array}$ & Negatif & $\begin{array}{c}\text { Memenuhi } \\
\text { syarat }\end{array}$ \\
\hline 3 & $\begin{array}{l}\text { Pseudomonas } \\
\text { aeruginosa }\end{array}$ & $\begin{array}{c}\text { TSB } \\
\text { CETA }\end{array}$ & $\begin{array}{c}\text { Koloni hijau metalik } \\
\text { Negatif }\end{array}$ & $\begin{array}{c}\text { Memenuhi } \\
\text { syarat }\end{array}$ \\
\hline 4 & Candida albicans & $\begin{array}{c}\text { PDB } \\
\text { Biggy }\end{array}$ & $\begin{array}{c}\text { Koloni coklat } \\
\text { kehitaman }\end{array}$ & Negatif & $\begin{array}{c}\text { Memenuhi } \\
\text { syarat }\end{array}$ \\
\hline
\end{tabular}

\section{PEMBAHASAN}

Obat tradisional merupakan obat yang berasal dari alam [tumbuhan, hewan, mineral] dan sediaan galeniknya, yang penggunaannya berdasarkan pengalaman, tanpa atau belum didukung oleh data klinis yang jelas.

Balsem ini merupakan suatu sediaan semipadat yang dibuat dari ramuan bahan alam dengan cara mengekstraksi dengan menggunakan bahan aktif minyak menguap berupa minyak kayu putih, minyak cengkeh, minyak sereh, minyak gandapura, minyak terpentin dan minyak permen.

Berbagai penelitian yang berkaitan minyak menguap ini telah dilakukan, terutama aktivitas antimikroba minyak cengkeh, minyak kayu putih dan minyak sereh dan hasilnya dapat menghambat pertumbuhan beberapa bakteri gram positif dan bakteri gram negatif. Disamping itu, pengalaman empiris dalam masyarakat telah membuktikan bahwa minyak-minyak menguap tersebut selain berkhasiat antimikroba, juga berfungsi sebagai karminatif dan dapat menghilangkan rasa nyeri.

Formula ini, menggunakan campuran bahan aktif tersebut yang diindikasikan untuk khasiat menghilangkan nyeri (counterirritant), pegal linu, encok, bengkak karena jatuh, salah urat, kepala pusing, masuk angin dan sakit pinggang. Rasa panas yang ditimbulkan oleh bahan aktif apabila digosokkan, dinetralisir dengan penambahan mentol yang memberikan efek rasa dingin pada kulit

Dalam pembuatan balsem ini, digunakan vaselin putih sebagai bahan dasar atau basis yang memiliki sifat inert sehingga memungkinkan bahanbahan obat lain dapat dicampurkan kedalamnya. Penambahan kombinasi cera alba yang berfungsi memberikan konsistensi yang lebih keras/padat 
pada balsem. Berdasarkan hasil orientasi, konsentrasi vaselin putih dan malam putih yang baik digunakan adalah $20 \%$ dan $15 \%$, dimana pada konsentrasi tersebut telah memberikan konsistensi balsem yang cukup padat.

Berdasarkan Keputusan Menteri Kesehatan RI No. 661/Menkes/SK/VII/1994, bahwa persyaratan obat tradisional dalam bentuk salep tidak boleh tengik. Ini teratasi dengan adanya kandungan komponen kimia dari bahan aktif minyak menguap yang berkhasiat sebagai pengawet.

Hasil pemeriksaan kualitatif terhadap bahan baku menunjukkan hasil yang positif. Sedangkan dari hasil pemeriksaan cemaran logam berat terhadap sediaan jadi yang meliputi cemaran tembaga [Cu], timbal [Pb], Raksa $[\mathrm{Hg}]$, dan arsen [As] tidak didapatkan hasil berupa perubahan warna yang sesuai dengan pustaka yang artinya sediaan Balsem yang diproduksi tidak tercemar logam-logam berat tersebut.

\section{Pemeriksaan}

secara

mikrobiologi terhadap sediaan jadi meliputi angka lempeng total bakteri, angka lempeng total kapang,uji Pseudomonas aeruginosa, uji Staphylococcus aureus, uji Escherichia coli, serta uji Salmonella thyposa. Pemeriksaan angka lempeng total bakteri, didapatkan hasil 2,0 $\times 10^{2}$ $\mathrm{kol} / \mathrm{g}$ sesuai dengan pustaka yaitu maksimal $3,0 \times 10^{3} \mathrm{kol} / \mathrm{g}$.. Pada pengujian terhadap Pseudomonas aeruginosa, Staphylococcus aureus, Escherichia coli serta Salmonella thyposa, didapatkan hasil yang negatif atau tidak tercemar bakteri dan jamur tersebut. Dari hasil tersebut, dapat disimpulkan bahwa Balsem telah memenuhi persyaratan secara mikrobiologis.

\section{KESIMPULAN}

1. Minyak menguap yang diindikasikan sebagai counterirritant akan memberikan efek optimal pada range konsentrasi tertentu.

2. Basis absorpsi yang digunakan akan menambah khasiat minyak menguap sebagai counterirritant

\section{DAFTAR PUSTAKA}

Anonim. 2006, Sentra Informasi IPTEK (online),(http://www.iptek.net. id/ind/pdtanobat/view.php?id $=13.17 \mathrm{~K}$, diakses Februari 2010)

Budiono J, 2007, Pertimbanganpertimbangan Pemilihan Basis Salep (online), http://www.kalbefarm a.com/files/12ruangBiofarma si008.pdf. diakses Maret 2010. 
Banker, G.S, and Rhodes, C.T, 1995, Modern Pharmaceutics. Third Edition, Marcel Dekker, Inc., New York.

Depkes. 1985. Swamedikasi. Jakarta : 82,84

Wasitaatmajaya, S. M., 1997, Penuntun IImu Kosmetik Medik, UI Press, Jakarta, 11, 27

Balsam, M. S., 1972, Cosmetic Science and Technology, Edisi 1, Interscience, London, 205, 224, 226.

Depkes, 1985, Tanaman Obat Indonesia, Direktorat Jenderal Pengawasan Obat dan Makanan, Jakarta : 63, 118, 223.

Ditjen POM, 1979, Farmakope Indonesia, Edisi III. Direktorat Jenderal Pengawasan Obat dan Makanan. Jakarta : 130, 362, 379, 453, 454, 455, 458, 633.

Tjitrosoepomo, G., 1989, Taksonomi Tumbuhan Obat-Obatan, UGM Press, Yogyakarta.

Heyne, K., 1987, Tumbuhan Berguna Indonesia, Jilid I, Departemen Kehutanan, Jakarta, 186, 1234.

Wijaya, K., 1998, Tanaman Berkhasiat Obat di Indonesia, Jilid IV, Pustaka Kartini, Jakarta.

Boyland, J. C., et All., 1986, Hand book of Pharmaceutical Exipients, American Pharmaceutical Association, New York, 3, 195, 241.
Direktorat Jenderal Pengawasan Obat dan Makanan, [1995]," Farmakope Indonesia ", Edisi IV, Departemen Kesehatan Republik Indonesia, Jakarta 167, 529, 791, 796, 822.

Direktorat Jenderal Pengawasan Obat dan Makanan.,[1979]," Kodeks Makanan Indonesia", Departemen Kesehatan Republik Indonesia, Jakarta 311.

Kibbe H., Arthur., [2000]," Hand Book of Pharmaceutical Excipients", Third edition, University School of Pharmacy Wilkes-Barre, Pensylvania, Washington.

Direktorat Jenderal Pengawasan Obat dan Makanan.,[1979]," Kodeks Kosmetika Indonesia", Departemen Kesehatan Republik Indonesia, Jakarta 158

Reynolds, J.E.F., [1999],"Martindale: The Complete Drug Reference", $32^{\text {th }}$ Edition, The Pharmaceutical Press, London 1127, 1367, 1527, 1578.

Guether, E, 1972, Minyak Atsiri, Jilid IV A. Terjemahan dari The Essential Oil oleh R. S. Ketaren dan R. Mulyono J, 1990, Penerbit Universitas Indonesia, Jakarta, 39-40, 74-76, 112-114.

Sasmitha, D. K., 1997, Card System dan Reaksi Warna, edisi revisi, Penerbit ITB Bandung, 14. 
Windhalz, M., Budavari, S., [1976] “ The Merck Index : An Enxyclopedia Of Chemicals and Drugs", $9^{\text {th }}$ Edition, Merck \& Co, Inc, New Jersey 1734.

United States Pharmacopeial Convention,[2003]," U.S. Pharmacopeia \& National Formulary, $21^{\text {th }}$ edition, United States Pharmacopeial Convention Inc. Rockville.
Svehla, G., [1990]," Vogel : Buku teks Analisis Anorganik Kualitatif Makro dan Semimikro", Edisi kelima, PT. Kalman Media Pustaka, Jakarta. 207, 212, 223, 229.

E. Merck., [1988], "Culture Media Handbook", Frankfurter Strasse 250, Federal republic of Germany, 124, 128, 131, 133, 137 